\title{
Expression of mRNA (Bcl-2, p53, Caspase 9, Caspase 3 and NGX 6) on Ovarium Carcinoma
}

\author{
Ardhanu Kusumanto ${ }^{1}$, Heru Prajadmo ${ }^{1}$, Indwiyani Astuti², Didik Setyo Herianto ${ }^{3}$ \\ ${ }^{1}$ Department of Obstetric \& Gynecology, Faculty of Medicine, Public Health and Nursing, Universitas Gadjah Mada, Yogyakarta, Indonesia \\ ${ }^{2}$ Department of Pharmacology \& Biomolecular, Faculty of Medicine, Public Health and Nursing, Universitas Gadjah Mada, Yogyakarta, \\ Indonesia \\ ${ }^{3}$ Department of Clinical Pathology, Faculty of Medicine, Public Health and Nursing, Universitas Gadjah Mada, Yogyakarta, Indonesia
}

\section{Email address:}

ardhanu_kusumanto@hotmail.com(A. Kusumanto)

\section{To cite this article:}

Ardhanu Kusumanto, Heru Prajadmo, Indwiyani Astuti, Didik Setyo Herianto. Expression of mRNA (Bcl-2, p53, Caspase 9, Caspase 3 and NGX 6) on Ovarium Carcinoma. American Journal of Clinical and Experimental Medicine. Vol. 8, No. 6, 2020, pp. 104-110.

doi: 10.11648/j.ajcem.20200806.12

Received: November 26, 2020; Accepted: December 11, 2020; Published: December 22, 2020

\begin{abstract}
Ovarian Cancer (OC) is a global health crisis and one of the deadly gynecological cancers among women worldwide. According to 2008-2012 U.S. cancer statistics, 12.7 per 100,000 women were newly diagnosed with ovarian cancer. During that same time period, the death rate was 7.7 per 100,000 women (Garcia et all, 2007, Wasana Sumanasekera et al 2018). Despite advances in medical and surgical treatment, attempts at early diagnosis, and a clearer picture of the etiology of this disease, increases in long-term survival have been small (Michael $\mathrm{G}$ et al, 1995). Because ovarian cancer is usually found at an advanced stage, the survival rate is lower than for other types of cancer (such as breast cancer) that are easier to detect at an early stage. If ovarian cancer is found early and treated, survival rates improve to more than $90 \%$. (Janet M et al. 2011). Data from various immuno-hystochemical researchs, in epithelial ovarian carcinoma (EOC) showed that protein expresion is able to predict the level of progessivity and respond of chemotherapy. The aim of the study is to evaluate the relationship between protein expresion of Bcl-2 $m R N A$, p53 $m R N A$, Caspase-9 $m R N A$, Caspase-3 $m R N A$ and NGX6 $m R N A$ in various prognostic factors and respond of cysplatin based chemotherapy for ephithel ovarian cancer (EOC). Result showed there were positive relationship between Bcl-2 mRNA and P53 mRNA with the hystological type, Grade and clinical stage of EOC, however there was a negative relationship with Caspase-9 mRNA, Caspase-3 mRNA dan NGX6 mRNA, especially for Caspase-9 mRNA showed signicantly lower $(\mathrm{p}=0.024)$. The study demonstrated a negative relationship between NGX6 mRNA, BCl-2 mRNA and P53 mRNA expresion with the respond of Chemotherapy to EOC, however there was a positive relationship between Casp9 mRNA and Casp3 mRNA. Summeries Various level and grade of Ovarian carcinoma have positive relationship with the expresion of Bcl-2 mRNA, p53 mRNA, and negative relationship with Caspase-9 mRNA, Caspase-3 mRNA and NGX6 mRNA. The study demonstrated a negative relationship between NGX6 mRNA, Bcl-2 mRNA and P53 mRNA expresion with the respond of Chemotherapy to EOC, however there was a positive relationship between Casp9 mRNA and Casp3 mRNA.
\end{abstract}

Keywords: Ovarian Carcinoma, Expresion of Bcl-2 Mrna, p53 Mrna, Caspase-9 Mrna, Caspase-3 Mrna and Ngx6 Mrna, Respond Chemotherapy

\section{Introduction}

Ovarian cancer is one of the most common causes of death from gynecological tumors. Ovarian cancer includes primary lesions that grow in the normal structure of ovarian tissue, and secondary cancer lesions originating from other parts of the body. $70 \%$ of all ovarian cancers are epithelial type ovarian cancers, or referred to as ovarian carcinomas [11, $18]$.

Although therapeutic outcomes have developed significantly in many solid cancers, the survival rate for women with ovarian carcinoma has only increased slightly since platinum-based therapy was discovered more than 30 
years ago, and eventhough there has been progress in reducing ovarian cancer incidence and mortality overall, further research is needed to determine the source of racial disparities and identify effective mechanisms for early ovarian cancer detection and prevention $[2,12,15,16]$. More than $70 \%$ of cases of ovarian carcinoma are diagnosed in an advanced stage due to lack of specific symptoms at an early stage. The survival rate for early stages is more than $90 \%$, while in advanced stages it is less than $30 \%$.

Data from various studies by immunohistochemistry in ovarian carcinoma shows that tumor markers/protein expression are thought to predict the level of progression and chemotherapy response and can facilitate ovarian carcinoma classification. Several proto-oncogens, tumor suppressor genes, and genes associated with apoptosis including Bcl-2, Bax, p53, p21, myc, ras, and HER-2/neu have been extensively studied in ovarian tumors $[4,8,9,19,20]$. Considering the heavy burden of ovarian cancer on women's health, preventive measures as well as health education and early detection in high risk groups of women are highly recommended. Although some risk factors cannot be changed, a focus on preventable risk factors may reduce the risk of ovarian cancer. More studies are needed to explore the role of unclear risk factors in ovarian cancer occurrence [10, 14].

Messenger RNA (mRNA) is a copy of the transcription of genes in DNA, and provides important information for protein molecules to be synthesized. mRNA is considered a protein chemical blueprint, because mRNA carries information from DNA to form protein strands. The main function of mRNA is to carry genetic codes from DNA in the cell nucleus to the ribosomes in the cytoplasm. mRNA binds to ribosomes in the cytoplasm and will determine the primary structure of a protein. Messenger RNA (mRNA) is a type of single strand RNA carrying information used to synthesize proteins [20]. Messenger RNA expression across different cell types was confirmed in primary ovarian cancer explans. As ovarian cancer is confined to the peritoneal cavity in most cases, the results create the basis of applications in which the tumor micro invirontment is transiently modified through protein expression [21].

NGX6 has a very important role as tumor suppressor in colon cancer, nasopharyngeal cancer and breast cancer, but the effect of NGX6 on the ovary is unclear. NGX6 is lowly expressed in nasopharyngeal carcinoma, and it can inhibit the proliferation and invasion of nasopharyngeal carcinoma cells, whose expression is positively correlated with the survival and prognosis of patients with nasopharyngeal carcinoma $[22,23]$. NGX6 is down-regulated in colorectal carcinoma, also in tumors that have metastasis and is associated with the clinical condition of the disease [24, 26]. In breast cancer NGX6 protein and mRNA levels were found to be lower in patients with tamoxifen resistant tumors compared to those who were sensitive. Tamoxifen has the ability to reduce proliferation, increase apoptosis and induce G1 arrest. NGX6 regulates the Smad family inside and outside the mitochondria which causes the release of cyclin D which plays a role in apoptosis [26].

What are the expressions of p53, Bcl-2, caspase 9, caspase 3 , and NGX6 mRNA in ovarian carcinoma and the relationship of the expressions of $\mathrm{p} 53, \mathrm{Bcl}-2$, caspase 9, caspase 3, and NGX6 mRNA with various prognostic factors for the success of ovarian carcinoma therapy is. How the relationship of the expressions of p53, Bcl-2, caspase 9, caspase 3, and NGX6 mRNA expression with the response of ovarian carcinoma therapy is.

The aim of this study is discovering the relationship between the expressions of mRNA p53, Bcl-2, Caspase 9, Caspase 3 and NGX6 with the response of ovarian carcinoma therapy, as well as looking into the relationship with various prognostic factors of ovarian carcinoma therapy.

\section{Material and Methods}

This research was conducted from September 2016 to June 2020 at the Department of Obstetrics and Gynecology, Dr. Sardjito Central General Hospital and the Department of Anatomy Pathology of the Faculty of Medicine, Public Health, and Nursing, Universitas Gadjah Mada of Yogyakarta Indonesia. The inclusion criterion in this research were the ovarian carcinoma patients, diagnosed and underwent primary surgery at the gynecological oncology clinic of Dr. Sardjito Central General Hospital. The exclusion criterion were the patients suffering from cancer other than ovarian carcinoma, the patients who have undergone therapy outside Dr. Sardjito Central General Hospital, and patients with incomplete medical records.

The sampling method used was non-probability consecutive sampling with independent variables expression of mRNA Bcl-2, p53, caspase 9, caspase 8, and NGX 6. The independent variable was the response of ovarian carcinoma therapy.

After being diagnosed clinically during surgery, the samples of the operated specimens were sent to the Anatomical Pathology Laboratory of the Faculty of Medicine, Public Health, and Nursing, Universitas Gadjah Mada. The measurement/isolation of mRNA by the RTqPCR examination method referred to the Hybrid- $\mathrm{R}^{\mathrm{TM}}$ Protocol for total RNA isolation.

The tabulated research data were then analyzed with SPSS 16-version for Windows. After that, several tests were conducted, including: One sample KS test to determine the normality and homogeneity of data, and correlation test using the Spearman test, followed by a linear regression test to determine the relationship between research variables. The data will be presented in tabular and narrative form.

\section{Results}

This research used a prospective cohort design by following 46 ovarian carcinoma patients whose ovarian tissue specimens were dissected and examined for diagnosis establishment (histological type, degree of differentiation, and clinical stage support) and biomolecular examination (mRNA), then continued to a therapy with platinum-based 
chemotherapy, and then the therapy response was viewed clinically (clinical imaging and complaints) and laboratory (Ca-125).

\subsection{Hystologic type}

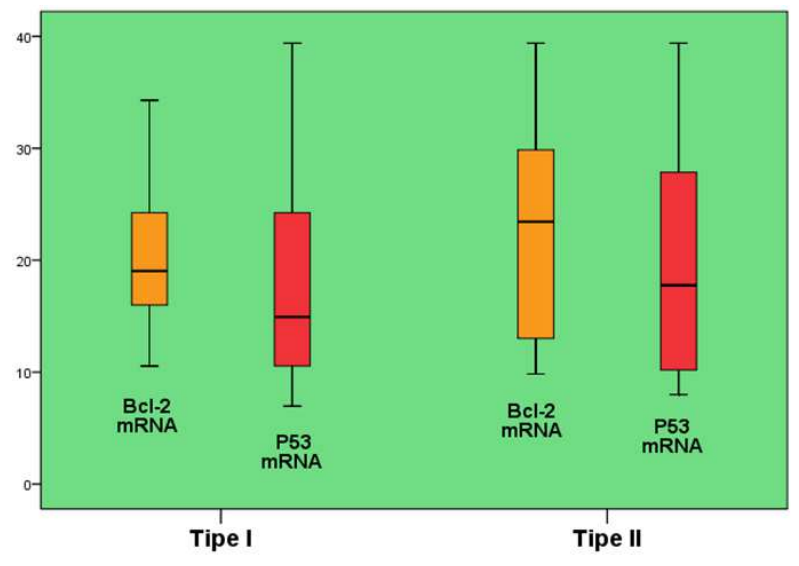

Histologic Type

\begin{tabular}{|c|c|c|c|c|l|}
\hline & \multicolumn{4}{|c|}{ Hystologic Type } & \\
\hline \multirow{4}{*}{} & \multicolumn{2}{|c|}{ I } \\
$\mathrm{n}=30$ & \multicolumn{2}{c|}{$\begin{array}{l}\text { II } \\
\mathrm{n}=16\end{array}$} & p-value \\
\cline { 2 - 6 } & Mean \pm SD & Median & Mean \pm SD & Median & \\
\hline Bcl-2 & $20.33 \pm 6.41$ & 19.03 & $21.98 \pm 9.45$ & 23.44 & 0.826 \\
\hline p53 & $17.77 \pm 9.11$ & 14.92 & $19.24 \pm 9.96$ & 17.76 & 0.712 \\
\hline
\end{tabular}

Figure 1. $m R N A$ expression of $B c l-2$ and $p 53$ and hystologic type.

There is a positive correlation between the mRNA expressions of $\mathrm{Bcl}-2$ and $\mathrm{p} 53$ and the histologic type of ovarian epithelial cancer; the higher the histologic type, the higher the mRNA expressions of Bcl-2 and p53 will be.

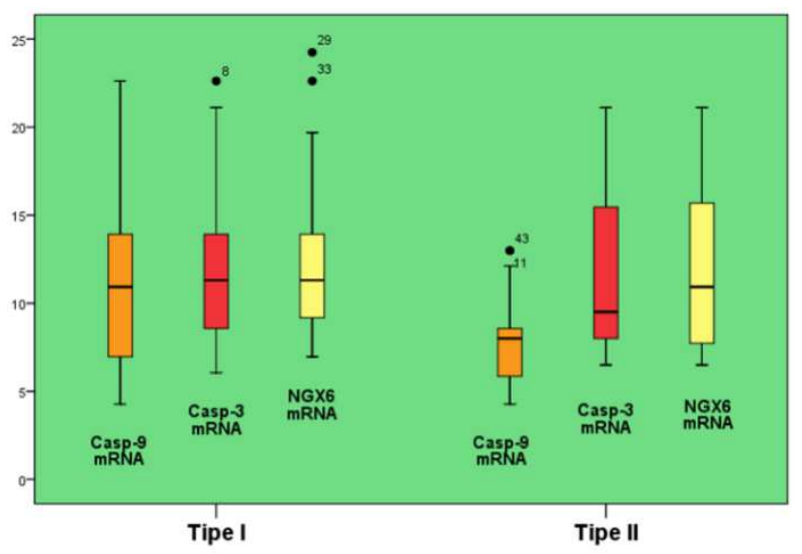

Hystologic Type

\begin{tabular}{|c|c|c|c|c|c|}
\hline & \multicolumn{3}{|c|}{ Hystologic Type } & \\
\hline & \multicolumn{2}{|c|}{$\begin{array}{c}\text { I } \\
\mathrm{n}=30\end{array}$} & \multicolumn{2}{c|}{$\begin{array}{c}\text { II } \\
\mathrm{n}=16\end{array}$} & $\mathrm{p}$-value \\
\cline { 2 - 6 } & Mean $\pm \mathrm{SD}$ & Median & Mean $\pm \mathrm{SD}$ & Median & \\
\hline Casp9 & $11.32 \pm 4.82$ & 10.93 & $7.97 \pm 2.72$ & 8.0 & $\mathbf{0 . 0 2 4}$ \\
\hline Casp3 & $11.71 \pm 4.17$ & 11.31 & $11.50 \pm 4.55$ & 9.51 & 0.781 \\
\hline NGX6 & $12.39 \pm 4.19$ & 11.31 & $11.76 \pm 4.96$ & 10.93 & 0.32 \\
\hline
\end{tabular}

Figure 2. mRNA expression of Casp-9, Casp-3, and NGX6 and hystologic type.
There is a negative correlation between the mRNA expressions of Casp-9, Casp-3, and NGX6 and the histologic type of ovarian epithelial cancer; the higher the histologic type, the lower the mRNA expressions of Casp-9, Casp-3, and NGX6.

\subsection{Degree of Differentiation}

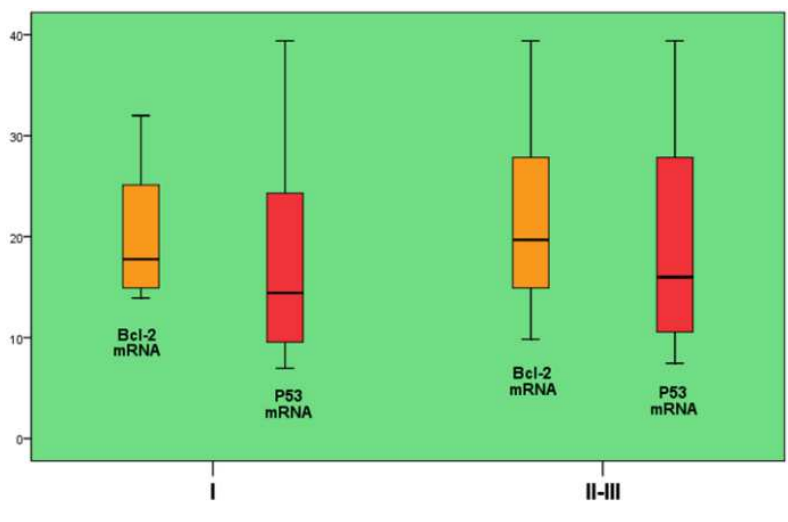

Degree of Differentiation

\begin{tabular}{|c|c|c|c|c|c|}
\hline & \multicolumn{3}{|c|}{ Degree of Differentiation } & \\
\hline \multirow{4}{*}{} & \multicolumn{2}{|c|}{$\begin{array}{c}\text { I } \\
\mathrm{n}=12\end{array}$} & \multicolumn{2}{c|}{$\begin{array}{c}\text { II-III } \\
\mathrm{n}=34\end{array}$} & p-value \\
\cline { 2 - 6 } & Mean \pm SD & Median & Mean \pm SD & Median & \\
\hline Bcl-2 & $20.34 \pm 6.62$ & 17.76 & $21.10 \pm 7.93$ & 19.69 & 0.831 \\
\hline p53 & $17.96 \pm 10.14$ & 14.42 & $18.40 \pm 9.19$ & 16.0 & 0.726 \\
\hline
\end{tabular}

Figure 3. $m R N A$ expression of Bcl-2 and p53 and degree of differentiation.

There is a positive correlation between the mRNA expressions Bcl-2 and p53 and the degree of differentiation of ovarian epithelial cancer; the higher the degree ofdifferentiation, the higher the mRNA expression of Bcl-2 and p53.

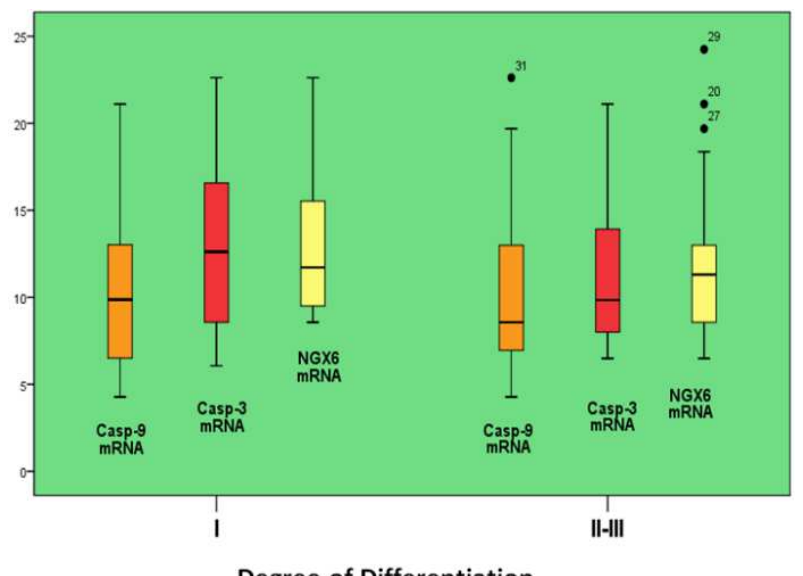

Degree of Differentiation

\begin{tabular}{|c|c|c|c|c|c|}
\hline & \multicolumn{3}{|c|}{ Degree of Differentiation } & \\
\hline \multirow{2}{*}{} & \multicolumn{2}{|c|}{$\begin{array}{c}\text { I } \\
\mathrm{n}=12\end{array}$} & \multicolumn{2}{c|}{$\begin{array}{c}\text { II-III } \\
\mathrm{n}=34\end{array}$} & p-value \\
\cline { 2 - 6 } & Mean \pm SD & Median & Mean \pm SD & Median & \\
\hline Casp9 & $10.29 \pm 4.79$ & 9.87 & $10.1 \pm 4.43$ & 8.57 & 0.970 \\
\hline Casp3 & $13.22 \pm 5.29$ & 12.62 & $11.08 \pm 3.75$ & 9.84 & 0.172 \\
\hline NGX6 & $13.11 \pm 4.56$ & 11.72 & $11.84 \pm 4.40$ & 11.31 & 0.322 \\
\hline
\end{tabular}

Figure 4. mRNA expression Casp-9, Casp-3, and NGX6 and degree of differentiation. 
There is a negative correlation between the mRNA expressions of Casp-9, Casp-3, and NGX6 and the degree of differentiation of ovarian epithelial cancer; the higher the degree of differentiation of ovarian epithelial cancer, the lower the mRNA expressions of Casp-9, Casp-3, and NGX6.

\subsection{Stage}

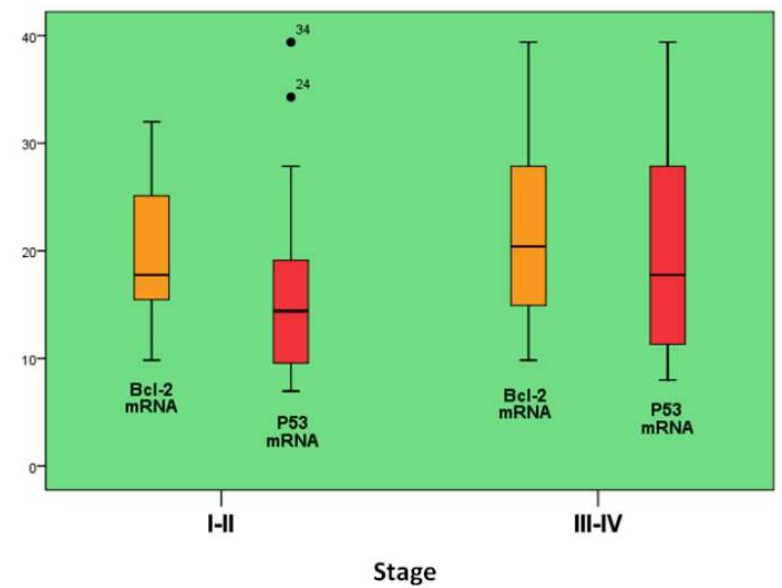

\begin{tabular}{|c|c|c|c|c|c|}
\hline & \multicolumn{3}{|c|}{ Stage } & \\
\hline \multirow{4}{*}{} & \multicolumn{2}{|c|}{$\begin{array}{c}\text { I-II } \\
\mathrm{n}=20\end{array}$} & \multicolumn{2}{c|}{$\begin{array}{c}\text { III-IV } \\
\mathrm{n}=26\end{array}$} & p-value \\
\cline { 2 - 6 } & Mean $\pm \mathrm{SD}$ & Median & Mean \pm SD & Median & \\
\hline Bcl2 & $19.92 \pm 6.80$ & 17.76 & $21.66 \pm 8.12$ & 20.40 & 0.556 \\
\hline P53 & $16.31 \pm 8.92$ & 14.42 & $19.80 \pm 9.53$ & 17.76 & 0.214 \\
\hline
\end{tabular}

Figure 5. $m R N A$ expression Bcl-2 and $p 53$ and ovarian cancer stage.

There is a positive correlation between the mRNA expressions of Bcl-2 and p53 and ovarian epithelial cancer stage; the higher the stage, the higher the mRNA expressions of Bcl-2 and p53.

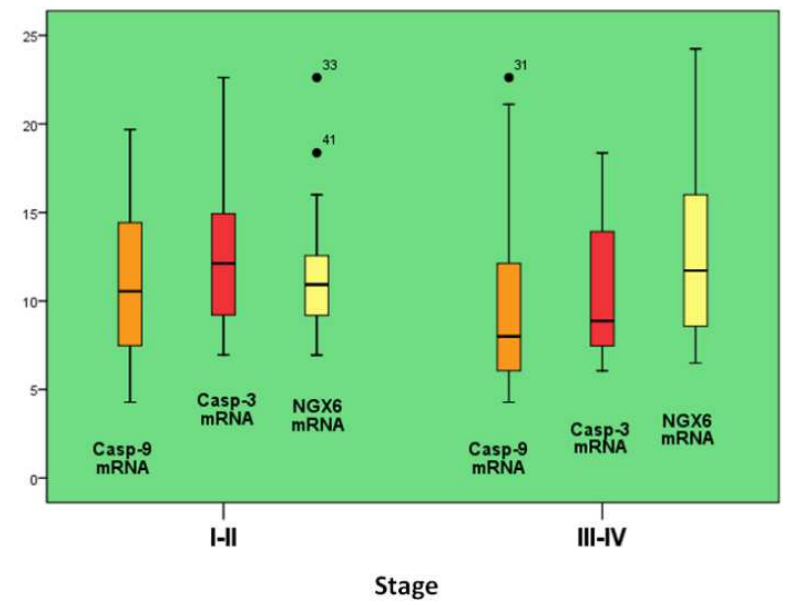

\begin{tabular}{|c|c|c|c|c|c|}
\hline & \multicolumn{4}{|c|}{ Stage } & \\
\hline & \multicolumn{2}{|c|}{$\begin{array}{c}\text { I-II } \\
\mathrm{n}=20\end{array}$} & \multicolumn{2}{c|}{$\begin{array}{c}\text { III-IV } \\
\mathrm{n}=26\end{array}$} & p-value \\
\cline { 2 - 6 } & Mean \pm SD & Median & Mean \pm SD & Median & \\
\hline \multirow{2}{*}{ Casp9 } & $10.82 \pm 4.25$ & 10.55 & $9.64 \pm 4.65$ & 8.0 & 0.226 \\
\hline Casp3 & $12.86 \pm 4.56$ & 12.12 & $10.70 \pm 3.82$ & 8.88 & 0.098 \\
\hline NGX6 & $11.62 \pm 3.74$ & 10.93 & $12.60 \pm 4.92$ & 11.72 & 0.609 \\
\hline
\end{tabular}

Figure 6. $m R N A$ expression Casp-9, Casp-3, and NGX6 and ovarian cancer stage.
There is a negative correlation between the mRNA expressions of Casp-9 and Casp-3 and the stage of ovarian epithelial cancer; the higher the stage, the lower the mRNA expressions of Casp-9 and Casp-3, except NGX6.

\subsection{Chemotherapy Reaction}

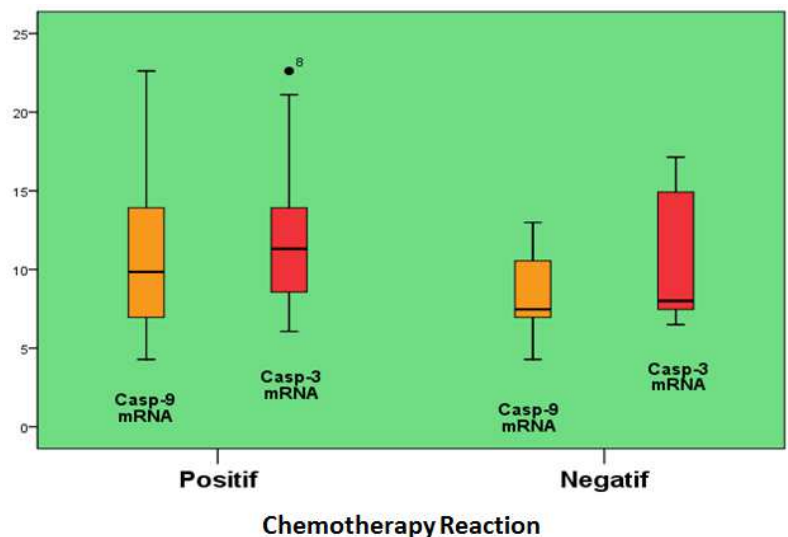

\begin{tabular}{|c|c|c|c|c|c|}
\hline & \multicolumn{4}{|c|}{ Chemotherapy Reaction } & \\
\hline & \multicolumn{2}{|c|}{ Positif } & \multicolumn{2}{c|}{ Negatif } & p-value \\
\cline { 2 - 6 } & Mean \pm SD & Median & Mean \pm SD & Median & \\
\hline Casp9 & $10.58 \pm 4.71$ & 9.84 & $8.39 \pm 2.92$ & 7.46 & 0.202 \\
\hline Casp3 & $11.80 \pm 4.27$ & 11.31 & $10.99 \pm 4.38$ & 8.00 & 0.496 \\
\hline
\end{tabular}

Figure 7. mRNA expression Casp-9 dan Casp-3 and chemotherapy reaction in ovarian epithelial cancer.

There is a positive correlation between the mRNA expressions of Casp-9 and Casp-3 and chemotherapy reaction in ovarian epithelial cancer; the higher the mRNA expressions of Casp- 9 and Casp-3, the higher/better the reaction to chemotherapy of ovarian carcinoma.

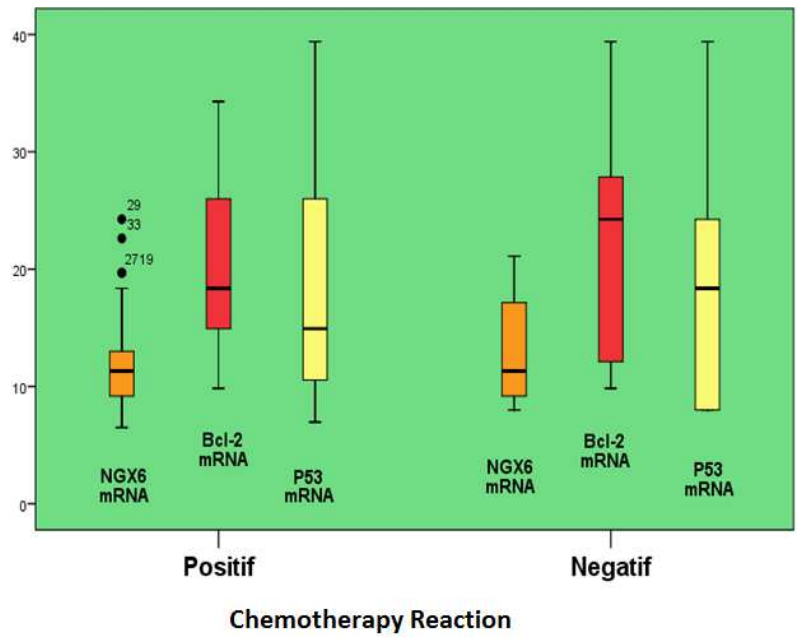

\begin{tabular}{|c|c|c|c|c|c|}
\hline & \multicolumn{4}{|c|}{ Chemotherapy Reaction } & \\
\hline & \multicolumn{2}{|c|}{ Positif } & \multicolumn{2}{c|}{ Negatif } & p-value \\
\cline { 2 - 6 } & Mean \pm SD & Median & Mean \pm SD & Median & \\
\hline NGX6 & $11.98 \pm 4.38$ & 11.31 & $12.96 \pm 4.81$ & 11.31 & 0.667 \\
\hline Bcl-2 & $20.52 \pm 6.95$ & 18.37 & $22.50 \pm 9.96$ & 24.25 & 0.718 \\
\hline p53 & $18.04 \pm 9.12$ & 14.92 & $19.29 \pm 10.61$ & 18.37 & 0.846 \\
\hline
\end{tabular}

Figure 8. mRNA expression NGX6, Bcl2 and p53 and chemotherapy reaction in ovarian epithelial cancer. 
There is a negative correlation between the mRNA expressions of NGX6, BcL-2, and p53 and the reaction to ovarian epithelial cancer therapy; the higher the mRNA expressions of NGX6, BcL-2, and p53, the lower/worse the reaction to chemotherapy of ovarian carcinoma.

In this research, a negative relationship was found between the expression of NGX6 mRNA, Bcl-2 mRNA and p53 mRNA with the therapeutic response to ovarian epithelial cancer. The negative therapeutic response value of NGX6 mRNA expression, Bcl-2 mRNA, and p53 mRNA value was higher than the positive response value and positive relationship between Casp-9 mRNA and Casp-3 mRNA expression with therapeutic response in ovarian epithelial cancer to chemotherapy. Positive therapeutic response value of Casp-9 mRNA and Casp-3 mRNA expression was higher than negative therapeutic response.

Patients who did not have a hormonal history were $80.4 \%$ compared to those who had a hormonal history of $19.6 \%$. Likewise, patients with no family history of having cancer in this research obtained $78.3 \%$ greater than patients who had a family history.

A total of $65.2 \%$ of patients had histologic type I and $73.9 \%$ of patients with degree II-III differentiation. In these patients, stages I-II and III-IV were almost the same, in stages III-IV it was slightly larger than stage I-II $(56.5 \%$ vs $43.5 \%$ ). In the inadequate tumor residues there were $71.7 \%$ compared to those inadequate $28.3 \%$, showing that of all cases it turned out that only $28.3 \%$ were adequately operated inadequately $71.7 \%$ because most of the patients coming to the hospital were in an advanced stage, and obtained malignant cells in its ascites $87.0 \%$

The positive ascites malignant cells were higher than the negative ones, the positive ones were $87 \%$ negative $13 \%$.

The average of p53 mRNA examination was 18.28 with standard deviation 9.33, on Bcl-2 mRNA, the average value was $20.90+7.55$. Casp-9 mRNA with mean $10.15+4.48$, Casp-3 mRNA $11.64+4.25$ and NGX6 mRNA examination $12.17+4.43$

\section{Discussion}

In this research, a negative correlation was found between NGX6 mRNA expression of $11.98+4.38$, Bcl-2 mRNA of mean $20.52+6.95$ and p53 mRNA of $18.04+9.14$ and positive therapeutic response to ovarian epithelial cancer. The negative therapeutic response was the mean value of NGX6 mRNA expression $12.96+4.81$, the mean Bcl-2 mRNA $22.50+9.96$ and the average p53 mRNA $19.29+$ 10.61 the value was higher than the positive response value, but there was no statistically significant difference $\mathrm{p}>0.05$.

The p53 gene (also called protein 53 or tumor protein 53), is a tumor suppressor protein that in humans is encoded by the TP53 gene. The p53 has an important role in multicellular organisms, where this protein regulates the cell cycle and its function as a tumor suppressor that plays a role in preventing cancer. P53 is described as "the guardian of genome", "the guardian angel gene", and "the master watchman", because of its important role in maintaining balance by preventing gene mutations [1, 5-7]. P53 IHC is a surrogate marker for p53 gene mutation in clinical practice. p53 positivity is seen in serous EOT, the expression being higher in high-grade serous carcinomas and in the advanced stage. It helps to differentiate between borderline and malignant tumors and high-grade from low-grade serous carcinomas. It can also assist in differentiating the endometrioid carcinomas from the serous types. Both staining patterns-diffuse staining and null positive patterns - are to be analyzed in routine practice. Null staining pattern deserves further studies for the association with its poorer prognosis. Hence, choosing an antibody clone which detects both wild and mutant staining is mandatory for p53 IHC. Understanding of p53 staining patterns is mandatory to use it along with a panel of other antibodies for the correct classification and further research of morphologically confusing EOT [17].

There was a positive relationship between the expression of Casp- 9 mRNA and Casp-3 mRNA with the therapeutic response of ovarian epithelial cancer to chemotherapy. The positive therapeutic response value of Casp9 mRNA and Casp3 mRNA expression was higher than negative therapeutic response but there was no statistically significant difference $\mathrm{p}>0.05$.

Caspase is a family of endoproteases that plays an important role in the regulatory tissue of inflammation and cell death. Caspase activation in the apoptotic process will result in the activation or inactivation of substrates which drive the signaling sequence that controls the destruction of cellular components. In this research, there was a negative relationship between the expression of Casp-9 mRNA, Casp-3 mRNA, and NGX6 mRNA with the histological type of ovarian epithelial cancer. Especially in Caspase-9 mRNA which statistically showed a significant difference $\mathrm{p}=0.024$

Caspase dysregulation causes a variety of diseases in humans including cancer and inflammatory disorders. According to the mechanism of action caspase can be divided into caspase initiator, e.g., caspase 9, and the excision of caspase, e.g., caspase 3

Activated death receptors will activate caspase 9, as the initiator caspase, will immediately initiate apoptosis and activate the excitatory caspase like caspase 3 , or indirectly by initiating an intrinsic pathway in the mitochondria that will activate caspase 9 which in turn activates the excitatory caspase such as caspase 3 , or indirectly by initiating an intrinsic pathway in the mitochondria that will activate caspase 9 which in turn activates the caspase 3 executioner [13].

In this research, a positive relationship was found between the expression of Bcl-2 mRNA and p53 mRNA with the histological type of ovarian epithelial cancer. The higher the histological type, the expression of Bcl-2 mRNA and p53 mRNA was higher, and there was also a positive relationship between the expression of Bcl-2 mRNA and p53 mRNA with the degree of differentiation of ovarian epithelial cancer.

In my previous study, it was found that the higher the 
woman's age, the lower the response of the treatment to chemotherapy treatment; and at the age of women $<50$ years, the treatment response was 7.58 times better than the age of women $>50$ years. In multivariable analysis of age, grade, and type of ovarian carcinoma, altogether assessing the chemotherapy response, it was found that age (OR. 5.8) and type (OR. 4) had a strong influence on cancer recurrence [27]. This is in accordance with Fei Deng, et al.[3], who argued that life expectancy for elderly women suffering from epithelial ovarian cancer is shorter than the younger age group. This difference in life expectancy seems to be caused by differences in the distribution of type or grade in the classification of the International Federation of Gynecology and Obstetrics (FIGO) or inadequate therapy [3, $25]$.

\section{Conclusion and Suggestions}

Based on the results of the research, the expressions of Caspase 9 and Caspase $3 \mathrm{mRNA}$ are found to be higher in ovarian carcinoma patients who have positive response, and lower in ovarian carcinoma patients who are not therapeutic response. In contrast, the expressions of Bcl-2, p53, and NGX 6 mRNAs are found to be higher in ovarian carcinoma patients who are not therapeutic response, and lower in ovarian carcinoma patients who are therapeutic response.

The expressions of Bcl-2, p53, Caspase 9, Caspase 3, and NGX 6 mRNA are considered to be potential non-invasive biomarkers in ovarian carcinoma cases. Even though the results of the research were statistically significant, they were still clinically visible. The use of mRNA as one of the prognostic factors for the success of carcinoma therapy is still very varied, related to the variation of each individual. Future further studies with larger populations are needed to further investigate the role of mcla Bcl-2, p53, Caspase 9, Caspase 3 and NGX 6, as well as other genes in the apoptotic pathway, as well as other cell death processes in determining the prognosis for success ovarian carcinoma therapy.

\section{Conflict of Interest}

I declare that there were no conflicts of interest in this study.

\section{Acknowledgements}

I am thankful to Prof. Heru Prajadmo and dr. Fahmi from the sub-division of Gynecological oncology for helping me with the data retrieval.

\section{References}

[1] ClaraIngaramo M, Sánchez JA, Dekanty A: Regulation and function of p53: A perspective from Drosophila studies Elsevier, Mechanisms of Development, (154): 82-90, December 2018.
[2] Coleman, M. P., Forman, D., Bryant, H., Butler, J., Rachet, B., Maringe, C., Nur, U., Tracey, E., Coory, M., Hatcher, J., McGahan, C. E., Turner, D., Marrett, L., Gjerstorff, M. L., Johannesen, T. B., Adolfsson, J., Lambe, M., Lawrence, G., Meechan, D., ... Richards, M. A. (2011). Cancer survival in Australia, Canada, Denmark, Norway, Sweden, and the UK, 1995-2007 (the international cancer benchmarking partnership): An analysis of population-based cancer registry data. The Lancet, 377 (9760), 127-138. https://doi.org/10.1016/S0140-6736(10)62231-3.

[3] Deng, F., Xu, X., Lv, M., Ren, B., Wang, Y., Guo, W., Feng, J., \& Chen, X. (2017). Age is associated with prognosis in serous ovarian carcinoma. J. f Ovarian Research, 10 (1), 1-9. https://doi.org/10.1186/s13048-017-0331-6.

[4] Fauvet, R., Dufournet, C., Poncelet, C., Uzan, C., Hugol, D., \& Daraï, E. (2005). Expression of pro-apoptotic (p53, p21, bax, bak and fas) and anti-apoptotic (bcl-2 and bcl-x) proteins in serous versus mucinous borderline ovarian tumours. J. Surg Oncol, 92 (4), 337-343. https://doi.org/10.1002/jso.20424.

[5] Ghosh, A., Stewart, D., \& Matlashewski, G. (2004). Regulation of Human p53 Activity and Cell Localization by Alternative Splicing. Mol. Cell. Biol, 24 (18), 7987-7997. https://doi.org/10.1128/mcb.24.18.7987-7997.2004.

[6] Isobe, M., Emanuel, B. S., Givol, D., Oren, M., \& Croce, C. M. (1986). Localization of gene for human p53 tumour antigen to band $17 \mathrm{p} 13$. Nature, 320 (6057), 84-85. https://doi.org/10.1038/320084a0.

[7] Kern, S. E. (1994). p53: Tumor suppression through control of the cell cycle. Gastroenterology, 106 (6), 1708-1711. https://doi.org/10.1016/0016-5085(94)90431-6.

[8] Kerr, J., Wyllie, A., \& Currie, A. (2005). Apoptosis: A basic biological phenomenon with wide-ranging implications in human disease. J. Internal Med., 258 (6), 479-517. https://doi.org/10.1111/j.1365-2796.2005.01570.x.

[9] Kim, D. J., Lee, M. H., Park, T. I., \& Bae, H. I. (2006). Expression and mutational analysis of c-kit in ovarian surface epithelial tumors. Journal of Korean Medical Science, 21 (1), 81-85. https://doi.org/10.3346/jkms.2006.21.1.81.

[10] Lheureux S, Braunstein M, Oza AM: Epithelial Ovarian Cancer: Evolution of Management in the Era of Precision Medicine, CA Cancer J Clin 2019; 69: 280-304.

[11] Lindsey A. Torre, Britton Trabert, Carol E. DeSantis, Kimberly D. Miller, Goli Samimi, Carolyn D. Runowicz, Mia M. Gaudet, Ahmedin Jemal, and Rebecca L. Siegel: Ovarian Cancer Statistics, 2018 CA Cancer J Clin. 2018 Jul; 68 (4): 284-296.

[12] McGuire, W. P. (2009). Maintenance therapy for ovarian cancer: Of Helsinki and Hippocrates. Journal of Clinical Oncology, $27 \quad$ (28), 4633-4634. https://doi.org/10.1200/JCO.2009.23.6653.

[13] Mcllwain, D. R., Berger, T., \& Mak, T. W. (2013). Caspase functions in cell death and disease. Cold Spring Harbor Perspectives in Biology, 5 (4), 1-28. https://doi.org/10.1101/cshperspect.a008656.

[14] Momenimovahed Z, Tiznobaik A, Taheri S and Salehiniya H: Ovarian cancer in the world: epidemiology and risk factors, Int J Womens Health. 2019; 11: 287-299. Published online 2019 Apr 30. doi: 10.2147/IJWH.S197604. 
[15] Omura, G., Blessing, J. A., Ehrlich, C. E., Miller, A., Yordan, E., Creasman, W. T., \& Homesley, H. D. (1986). A randomized trial of cyclophosphamide and doxorubicin with or without cisplatin in advanced ovarian carcinoma. A gynecologic oncology group study. Cancer, 57 (9), 17251730 .

0142(19860501)57:9<1725::AIDhttps://doi.org/10.1002/1097-

CNCR2820570903>3.0.CO;2-J.

[16] Palmen E' Ebisch I, Dolstra H, Mattias Hällbrink, Leon F A G Massuger, Roland Brock Dirk van den Brand Mark A J Gorris, Alexander $\mathrm{H}$ van Asbeck, et al: Peptide-mediated delivery of therapeutic mRNA in ovarian cancer. Eur J Pharm Biopharm. 2019 Aug; 141: 180-190. doi: 10.1016/j.ejpb.2019.05.014. Epub 2019 May 16.

[17] Razak Amanullah NA, Poothiode U, Vilasiniamma L: Expression of P53 in epithelial ovarian tumors: Indian J, Patol, Microbiol 2020; 63: 235-40.

[18] Reid, B. M., Permuth, J. B., \& Sellers, T. A. (2017). Epidemiology of ovarian cancer: a review. Cancer Biology and Medicine, 14 (1), 9-32. https://doi.org/10.20892/j.issn.2095-3941.2016.0084.

[19] Schuyer, M., Van der Burg, M. E. L., Henzen-Logmans, S. C., Fieret, J. H., Klijn, J. G. M., Look, M. P., Foekens, J. A., Stoter, G., \& Berns, E. M. J. J. (2001). Reduced expression of BAX is associated with poor prognosis in patients with epithelial ovarian cancer: A multifactorial analysis of TP53, p21, BAX and BCL-2. British Journal of Cancer, 85 (9), 1359-1367. https://doi.org/10.1054/bjoc.2001.2101.

[20] Skirnisdóttir, I., Sorbe, B., \& Seidal, T. (2001). P53, bcl-2, and bax: Their relationship and effect on prognosis in early stage epithelial ovarian carcinoma. International Journal of
Gynecological Cancer, $11 \quad$ (2), 147-158. https://doi.org/10.1046/j.1525-1438.2001.01003.x.

[21] Solomon, E., Martin, C., Martin, D. W., \& Berg, L. R. (2008). Biology (8th ed.). Thomson Brooks/Cole.

[22] Tavassoli, F., \& Devilee, P. (2003). Pathology and Genetics: Tumours of the Breast and Female Genital Organs. IARC Press.

[23] Wang YT, Sun XY, Wang H, Huang TT, Wang Y, Yang MX, Effects of NGX6 expression on proliferation and invasion of nasopharyngeal carcinoma cells and survival of patients, Eur Rev Med Pharmacol Sci. 2017 Dec; 21 (23): 5378-5385. doi: 10.26355/eurrev_201712_13923.

[24] Xiao, J., Zhou, Y., \& Zhu, W. (2015). Association of ultrasonographic features with NGX6 expression and prognosis in invasive ductal breast carcinoma. International Journal of Clinical and Experimental Pathology, 8 (6), 6458-6465.

[25] Xu, X., Deng, F., Lv, M., Ren, B., Guo, W., \& Chen, X. (2016). Ascites regression following neoadjuvant chemotherapy in prediction of treatment outcome among stage IIIc to IV high-grade serous ovarian cancer. Journal of Ovarian Research, 9 (1), 1-8. https://doi.org/10.1186/s13048016-0294-z.

[26] Zhao, W. J., \& Wang, K. (2013). NGX6 expression improves the sensitivity of tamoxifen-resistant MCF-7 cells through modulation of the Smad signaling pathway. International Journal of Oncology, 42 (6), 2060-2068. https://doi.org/10.3892/ijo.2013.1886.

[27] Ardhanu Kusumanto.(2020). Platinum based chemotherapy for Ovarian carcinoma, Bali med. J, (9) 1: 404-407. P-ISSN. 2089-1180, E-ISSN. 2302-2914. 